\title{
Weitere Beiträge \\ zur Bakteriologie der Keratitis des Menschen, insbesondere der eitrigen.
}

\author{
Von \\ W. Uhthoff und Th. Axenfeld \\ in Breslau. \\ Mit Tafel VII. \\ (Aus der Universitäts-Augenklinik zu Breslau.)
}

Die vorliegenden kurzen Mittheilungen sind bestimmt, zu unseren früheren „Beiträgen zur pathologischen Anatomie und Bakteriologie der eitrigen Keratitis des Menschen" (v. Graefe's Archiv f. Ophthalm. XLII. Abth. 1) noch neue Untersuchungsergebnisse auf diesem Gebiete zu bringen, die uns geeignet erscheinen, das früher Mitgetheilte zu ergänzen resp. zu vervollständigen. So stattlich eine-Anzahl von 50 untersuchten Fällen auch erscheinen mag, so kann sie doch nicht ausreichen, um über eine Reihe von Punkten ein definitives Urtheil zu gewinnen, und manche Frage bedarf noch der weiteren Discussion. In diesem Sinne haben wir unsere Untersuchungen noch regelmässig fortgeführt, so dass wir jetzt über ein neues Material von 68 weiteren Fällen rerfügen.

Aus dem Schluss unserer damaligen Arbeit möge ein Satz hier noch einmal wörtlich angeführt werden, der die Richtung kennzeichnet, in der die Untersuchungen in erster Linie fortgeführt wurden. Wir sagten an jener Stelle mit 
Weitere Beiträge z. Bakteriologie d. Keratitis des Menschen etc. 173

Bezug auf das Ulcus corneae serpens: „Wir heben ausdrücklich hervor, dass nach unserer Ueberzeugung Mischinfectionen vorkommen und damit auch weniger markante Krankheitsbilder; ebenso wird der Grad der Virulenz, die Widerstandsfähigkeit des lebenden Gewebes, sowie die Art einer ursächlichen Verletzung u. s. w. modificirend wirken können, wie dies für alle Körperorgane auch sonst zutrifft, ohne dass dadurch jedoch die typischen Bilder umgestossen werden. Es ist diese qualitativ differente Wirkung der genannten Eitererreger für die Cornea ein neuer Hinweis, in wie feiner Weise sich hier unter Umständen entzïndliche Vorgänge differenciren."

Folgende specielle weitere Fragen bedürfen sowohl vom klinischen als bakteriologischen Standpunkte der erneuten Untersuchang:

1. $\mathrm{Ob}$ es sich auch ferner bestätigt, dass bei dem typischen Ulcus corneae serpens stets eine PneumocokkenInfection der Hornhaut vorliege (natïrlich bei Anwendung geeigneter Nährböden), und wie oft diese Mikroorganismen in Reincultur bei diesem Hornhautprocess gefunden werden.

2. Ob eine Pneumocokken-Infection der Cornea immer unter dem Bilde des Ulcus corneae serpens verläuft, und wie weit z. B. die Eigenart (Tiefe u. s. w.) der Verletzung im Stande ist, das Bild zu modificiren. Ferner in wie weit bei einer atypischen Hypopyonkeratitis mit Pneumocokken gleichzeitig noch andere Mikroorganismen gefunden werden und ob eine Vergesellschaftung mit anderen Mikroorganismen dann die Regel ist.

Auch möchten wir uns von vornherein mit Rücksicht auf Angaben in einigen Referaten über unsere Arbeit ausdrücklich dagegen verwahren, dass wir behauptet hätten, eine Pneumocokken-Infection der Cornea könne nur typisches Ulcus serpens hervorbringen. Wir haben damals nur die Resultate unserer 50 Fälle mitgetheilt, in denen sich Pneumocokken thâtsächlich nur bei Ulcus serpens gefunden 
haben. Aber unsere Behauptung, die wir auch heute noch vollkommen aufrecht erhalten, dass das Ulcus serpens mit verschwindenden Ausnahmen eine Pneumocokken-Infection ist, darf nicht identificirt werden mit der Ansicht, dass Pneumocokken stets ein Ulcus serpens erzeugen müssten. Der oben citirte Satz unserer damaligen Arbeit beweist wohl zur Genüge, dass unsere Schlussfolgerungen in dieser Hinsicht nicht $\mathrm{zu}$ weit gingen.

3. Erschien es uns besonders wünschenswerth, auch die allerfrühsten Stadien des Ulcus serpens bakteriologisch zu untersuchen und der Frage näher zu treten, in wie weit etwa der positive Pneumocokken-Befund beim ganz frischen Cornealinfiltrat uns berechtigt, die Entwicklung eines typischen Ulcus serpens vorher zu sagen zu einer Zeit, wo der frische klinische Befund die Diagnose "Ulcus serpens" noch nicht rechtfertigt.

4. Ob die merkwürdige Thatsache, dass wir bei Kindern kein typisches Ulcus serpens in unserer ersten Untersuchungsreihe beobachten konnten, sich von Neuem bestätigen würde.

5. Wie zu dem bakteriologischen Befunde in der erkrankten Hornhaut sich derjenige des eventuell begleitenden Thränenleidens verhält.

6. War es uns erwünscht, noch in einer grösseren Anzahl von Fällen, wo bei Ulcus serpens Pneumocokken gefunden wurden, diese Mikroorganismen in Reincultur bei weissen Mäusen zu verimpfen, somit die typische Pneumocokken-Septicaemie bei denselben zu beobachten und gerade daraufhin die Möglichkeit der Differentialdiagnose zwischen Pneumocokken und den eigentlichen Streptocokken ron Neuem zu prüfen.

7. Fahndeten wir noch mit besonderem Interesse auf neue Fälle von Schimmel-Keratitis und können in dieser Hinsicht thatsächlich über eine weitere interessante Beobachtung berichten. 
Weitere Beiträge z. Bakteriologie d. Keratitis des Menschen etc. 175

Das neue von uns untersuchte Keratitismaterial betrifft weitere 68 Fälle und lässt sich nach seiner klinischen Erscheinungsweise folgendermaassen gruppiren:

I. Typisches Ulcus corneae serpens 34 Fälle.

II. Atypische Hypopyon-Keratitis 13 Fälle.

III. Keratomalacie bei Xerophthalmus . . . . . . . . . . 3 Fälle.

IV. Scrophulöse oberflächliche Keratitis . . . . . . . . 5 Fälle.

V. Keratitis dendritica . . . . 7 Fälle.

VI. Ulcus rodens corneae . . . . 1 Fall.

VII. Keratitis pannosa bei Trachom . 2 Fälle.

VIIT. Keratitis parenchymatosa e lue congenita . . . . . . . . . 1 Fall.

IX. Hornhautveränderungen bei Frühjahrskatarrh. . . . . . 1 Fall.

X. Keratomycosis aspergillina . . 1 Fall.

Man sieht aus dieser Zusammenstellung, dass es uns in erster Linie darum zu thun war, unsere Untersuchungen über die eitrige Keratitis des Menschen noch weiter zu führen und zu vervollständigen, und vor Allem wurde das typische Ulcus corneae serpens und die atypische Hypopyonkeratitis berücksichtigt. Wir verweisen in Bezug auf die Definition dieser beiden Krankheitsbilder auf unsere frühere Mittheilungen (l. c.).

\section{Das Ulcus corneae serpens}

und dessen bakteriologischer Befund (34 Fälle).

1. Nur Pneumocokken $25 \mathrm{Mal}$

(Hiervon acht Fälle jedoch nur im Deckglaspräparat untersucht, keine Culturen angelegt).

2. Pneumocokken in Verbindung mit anderen Mikroorganismen . . . . . . . $8 \mathrm{Mal}$

(Xerobacillen und Staphylocokken).

3. Diplobacillen ( + Pneumocokken?) . . $1 \mathrm{Mal}$ 
In allen Fällen von typischem Ulcus corneae serpens mit Ausnahme des letzten also wurden wiederum die Fraenkel-Weichselbaum'schen Pneumocokken nachgewiesen und zwar in der bei weitem grössten Mehrzahl der Fälle in Reincultur.

Die Entnahme des Materials und die Cultivirung der Mikroorganismen geschah analog, wie bei unseren früheren Untersuchungen, ebenso die Feststellung der Diagnose "Pneumocokken" unter den früher entwickelten Gesichtspunkten, nur dass bei dieser Untersuchungsreihe vielfach die Verimpfung der Reinculturen auf weisse Mäuse stattfand, um festzustellen, ob der gewöhnliche Befund der Pneumocokken-Septicaemie mit Kapseldiplocokken im Blut dadurch hervorgerufen wurde. Wir wollten uns durch dies Experiment überzeugen, in wie weit unsere Pneumocokken für die Maus pathogen seien, da dies früher für differentiell diagnostisch entscheidend gegenüber dem Streptococcus pyogenes gehalten wurde. Zunächst zeigte sich hierbei nun, dass die Diplocokken-Septicaemie bei der weissen Maus sich ziemlich immer erzielen liess, wenn man die frische OriginalBlutserumcultur und besonders deren Condenswasser zur Injection verwendete. Vom Agar aus, sowie bei mehrfacher Ueberimpfung war dies Resultat nicht regelmässig zu erzielen, da die Virulenz offenbar häufig sehr schnell abnimmt. Im Uebrigen baben auch wir uns davon überzeugen können, dass dieses Verhalten gegenïber der weissen Maus kein durchgreifendes Unterscheidungsmerkmal gegenüber den Streptocokken ist, wie dies von den Bakteriologen neuerdings besonders hervorgehoben wird. Auch wir haben bei der weissen Maus mit echten Streptocokken wiederholt tödtliche Septicaemieen mit Streptocokkenbefund im Blut entstehen sehen.

Die in einer Anzahl von Fällen neben den Pneumocokken gefundenen Mikroorganismen beschränken sich auf den Befund von spärlichen Xerosebacillen (4 Mal) und 
Staphylocokken (4 Mal) und zwar so, dass der Pneumocokkenbefund auch in diesen Fällen derartig überwiegt, dass man an der eigentlichen ätiologischen Bedeutung des Pneumococcus auch hier nicht zweifeln konnte.

In 12 Fällen war die Complication eines eitrigen Thränenleidens vorhanden (also in etwas über ein Drittel der Fälle), 1 mal Trachom und 1 mal Conjunctivitis chronica.

In 5 von diesen Fällen wurde gleichzeitig die bakteriologische Untersuchung des Thränensacksecretes durchgeführt. Auch hier wurden stets Pneumocokken gefunden, jedoch nur 2 mal in Reincultur, in den drei anderen Fällen vergesellschaftet mit anderen Mikroorganismen (Bacillen, Staphylocokken, Ozaenabacillen). Aber auch in zweien dieser drei letzten Fälle enthielt das Ulcus serpens nur Reinculturen von Pneumocokken, während der Befund im Thränensack ein mannigfacher war.

Nur einige wenige Krankengeschichten sollen von diesen 34 Fällen hier kurz angeführt werden, die besonders bemerkenswerth erscheinen. Zunächst eine Gruppe von fünf Fällen, wo das Ulcus serpens in den allerersten Stadien zur Beobachtung kam, so dass die Diagnose „Ulcus serpens" am ersten Tage klinisch noch nicht gestellt werden konnte und erst die nächste Zeit das typische Bild brachte. In allen fünf Fällen wurden sowohl im Deckglaspräparat als auf den Nährböden die Pneumocokken in Reinkultur gefunden.

Die fünf Beobachtungen sind folgende:

Fall I.

17. VIII. 96. Landmann Joh. Dittmann, 69 Jahre alt, leidet seit 24 Jahren an Trachom; das rechte Auge war auch in der Kindheit entzündet, seit der Zeit Hornhautflecke auf demselben.

Linkes Auge: Seit dem 15. VII. 96 zunehmende Entzündung ohne bekannte Ursache, doch hat Patient im Walde gearbeitet. Status praesens: Linkes Auge. Auf der Hornhaut central, rundes, etwas geblähtes, gelbes oberflächliches Infiltrat von $2 \mathrm{~mm}$ 
Durchmesser, nach unten und den Seiten durch eine seichte Rinne gegen die Umgebung abgesetzt, nach oben noch etwas fester anhaftend, hier auch einige kleine gelbliche Punkte. Beginnende Auflagerung auf der Hinterfläche der Cornea, Kammerwasser im unteren Theil der vorderen Kammer etwas fleckig (beginnende Hypopyonkeratitis, aber noch kein typisches Ulcus corneae serpens).

Beim kräftigen Abspülen mit sterilisirtem Wasser löst sich das ganze Infiltrat bis anf wenige Verbindungen oben innen, doch bleiben, unter der Loupe gesehen, am Rande der nun entstandenen, facettenartigen Delle mehrere kleine graugelbliche Infiltrationspunkte, besonders am inneren Rande.

Das abgehobene Stück ist ziemlich zähe, lässt sich aber leicht zerzupfen. Ein kleines Theilchen wird in physiologischer Kochsalzlösung unter dem Deckglas glatt gedrückt und durch zufliessendes Methylenblau gefärbt. Man erkennt dann an der Oberfläche noch Reste von Lamellenschichtung, doch dazwischen und in dem ganzen Stïck dichte Reinkulturen kapselumgebener länglicher Diplocokken resp. Kurzstäbchen.

Die Cultivirung anf Blutserum ergiebt Reincultur von Pneumocokken. Das Condenswasser der Cultur wird einer weissen Maus unter die Rückenhaut injicirt. Tod nach 36 Stunden, DiplocokkenSepticaemie mit zahlreichen Kapseldiplocokken im Blut.

Am folgenden Tage hat der Hornhautprocess das Aussehen eines kleinen typischen Uleus serpens mit progressivem Rande und wird dureh die Galvanokanstik geheilt.

\section{Fall II.}

11. VII. 96. Anna Scherer, 28 Jahre alt, will vor vier Jahren schon einmal an einem von selbst entstandenem "Fell" auf dem Auge gelitten haben, auf welchem, weiss sie nicht mehr. Nach der spontanen Heilung hat Patientin angeblich wieder gut gesehen.

Jetzt am 7. VII. hat sie sich das rechte Auge mit einer Aehre verletzt, am nächsten Morgen Beginn der Beschwerden, seit gestern hat der Mann das "Fleckehen" bemerkt. Ein Thränen des Auges soll bis dahin nicht bestanden haben.

Statns praesens: Schwächliche, aber im Allgemeinen gesunde Frau. - Linkes Auge normal. - Rechtes Ange zeigt starke pericorneale Injection. Centrales $3 \mathrm{~mm}$ breites, rundes, noch geschlossenes Infiltrat, gleichmässig gesättigt, etwas gebläht, noch 
ziemlich oberflächlich. Uebrige Cornea, besonders in der Umgebung und nach unten rauchig grangelblich getrübt. Bisher kein deutliches Hypopyon, doch ausgesprochene Hyperaemie der Iris (also bis jetzt kein typisches Bild von Uleus corneae serpens).

Bei Entnahme des Impfmaterials lassen sieh die centralen Theile des Infiltrates sehr leicht abkratzen, sind butterweich, während die Ränder derber und infiltrirt bleiben.

Im Deckglas sowohl als auf Blutserum-Reincultur von länglichen vielfach kapselumgebenen Diplocokken (Pneumocokken, nach Gram färbbar).

Es wird sofort mit gutem Erfolg die Galvanokaustik angeschlossen. - Ob sich in diesem Falle der Process zu einem typischen Ulcus cormeae serpens entwickelt hätte, konnte wegen sofortiger Ausführung der Galvanokaustik nicht sicher entschieden werden, doch bot das Bild nach der Entnahme des Materials, namentlich in Bezug auf den Geschwürsrand schon manche Analogieen.

Fall III.

9. V. 96. Frau Katharina Metz hat sich nach einer Verletzung vor einigen Tagen eine Entzündung ihres rechten Auges zngezogen. Nahe dem Hornhautcentrum ein etwas über stecknadelkopfgrosses, gelbliches, oberflächliches Infiltrat, das innen oben und unten sich breit von der Umgebung gelöst hat, aussen jedoch noch fester am Gewebe haftet (bisher kein für Uleus serpens typisches Bild). - Auf der Hinterfliache graugelbliche Anlagerungen in Gestalt einer rundlichen Figur, ganz geringes Hypopyon.

Bei Entfernung (Auskratzung) des Infiltrates, das sich in toto, pfropfartig loslösen lässt, bleibt der Rand, wo dasselbe festhaftete stärker grau infiltrirt, so dass jetzt etwas Aehnlichkeit mit Uleus serpens schon besteht. Sowohl im Deekglas, als auf dem Blutserum typische Reinkulturen von Kapseldiplocokken (Pneumocokken).

Nach zwei Tagen, als Patient sich wieder vorstellt, besteht das typische Bild des Ulcus serpens mit progressivem Rande und erhebliclem Hypopyon.

Fall IV.

2. III. 97. Fran Zukunft, 40 Jahre alt, hat sich vor vier Tagen das linke Ange beim Dreschen verletzt, worauf sich eine Entzündung dieses Auges entwickelte. 
Status praesens: Rechtes Auge normal. - Linkes Auge: Kleines rundes gelblich graues Infiltrat (etwas über stecknadelkopfgross), ziemlich im Centrum der Hornhaut, das darüber liegende Epithel etwas vorwölbend. Ein Defeet nicht deutlich sichtbar. Um das Infiltrat herum ein tiefliegender grauer Hof, starke pericorneale Injection, Iritis, kleines Hypopyon in der vorderen Kammer.

Mit der Lanze wird ans dem Infiltrat etwas Material entnommen, welches sich ziemlich zäh erweist und nach unten fest haftet.

Im Deckglas Reinculturen von massenhaften Diplocokken mit überans deutlichen Kapseln. Gram'sche Färbung positiv.

Die Cultivirung auf verschiedenen Nährboden (Blutserum, Glycerin-Agar, Bouillon) ergiebt gleichfalls Reinculturen von Pneumocokken. Die Impfung einer weissen Maus mit $2 \mathrm{ccm}$ Bouilloneultur tödtet dieselbe nicht.

Am Tage der ersten Vorstellung wird eine Galvanokaustik nicht ausgeführt, am folgenden Tage ist der Process etwas fortgesehritten und zeigt jetzt schon deutlich den Charakter des typischen Uleus corneae serpens mit progressivem Rande nach unten aussen. Heilung durch Galvanokaustik.

Fall V.

14. VI. 96. Frau Geide leidet seit längerer Zeit an chronischer Daeryocystoblennorrhoe. Seit einigen Tagen auf dem linken Auge ohne bekannte Ursache zunehmende Entzïndung. Bei der Aufnahme in die Klinik findet sich in der linken Hornhaut ein stecknadelkopfgrosses graugelbes centrales oberflächliches Infiltrat, dasselbe ist noch nicht zerfallen (kein für Uleus serpens typisches Bild). Die übrige Cornea leicht rauchig getrübt, in der Tiefe hinter dem Infiltrat rundlicher Hof (hinterer Reizbezirk). Bisher noch kein Hypopyon, mässige Iritis.

Es wird mit spitzer Lanze Material aus dem Infiltrat entnommen und sowohl im Deckglas untersucht, als auf Blutserum übertragen. Der Befund zeigt Reinculturen der länglichen, vielfach kapselumgebenen Diplocokken (Pneumocokken), dieselben. färben sich nach Gram.

Am folgenden Tage 15. VI. 96 hat der Process das Aussehen eines kleinen typisehen Ulcus corneae serpens mit nasalwärts gelegenem progressiven infiltrirtem Rande, während der temporale Rand sich gereinigt hat. 
Weitere Beiträge z. Bakteriologie d. Keratitis des Menschen etc. 181

Die eben angeführten Krankengeschichten zeigen zunächst, dass das Ulcus corneae serpens im allerersten Stadium nicht immer schon ein typisches Bild bietet, sondern sich zunächst unter dem Bilde eines nicht typischen Infiltrates darstellen kann, dem sich dann erst in den nächsten Tagen die Entwicklung des typischen Bildes anschliesst. Gerade in diesen Fällen ist die bakteriologische Untersuchung von Bedeutung; findet sich der Pneumococcus in Reincultur, so steht die Ausbildung eines Ulcus corneae serpens in allernächster Zeit zu erwarten, und gerade diese Fälle erfordern in erster Linie die galvanokaustische Behandlung, auch im allerfrühsten Stadium. Wir haben uns wiederholt durch den bakteriologischen Befund in Bezug auf die Therapie leiten lassen. Mehrmals haben wir beobachten können, dass die anfängliche Unterlassung der Galvanokaustik bei relativ kleinen eitrigen Hornhautinfiltraten mit Pneumocokkenbefund sich dadurch rächte, dass die Patienten in allernächster Zeit mit einem ausgesprochenen Ulcus corneae serpens sich wieder vorstellten, während bei einem anderen bakteriologischen Befunde dies Fortkriechen in die Fläche weniger zu befürchten ist und es somit eher gegerechtfertigt erscheint, den galvanokaustischen Eingriff namentlich bei centralem Sitz des Heerdes anfangs zu unterlassen, um nicht unnütz Hornhautsubstanz durch allzu energisches Eingreifen zu opfern. - Bei der Entnahme eines beginnenden serpiginösen Infiltrates pllegt übrigens dasselbe an der Seite dem Hornhautgewebe fester anzuhaften, wo in der nächsten Zeit der progressive Rand sich ausbildet.

Die bei Weitem grösste Mehrzahl unserer Fälle bieten vom klinischen Gesichtspunkte nichts Besonderes, so dass. die Mittheilung derselben unterbleiben kann.

Drei Fälle verdienen sodann noch einer besonderen Erwähnung insofern, als sie anfangs von dem typischen Bilde des Ulcus serpens etwas abwichen, im späteren Ver- 
lauf jedoch die charakteristischen Merkmale des Processes zeigten, so dass sie mit unter die Gruppe "Ulcus serpens" aufzunebmen waren. Zwei dieser Fälle sollen hier noch kurz mitgetheilt werden, sie zeigten, wie wir glauben, dass durch die Art und Weise sowie die Tiefe der Verletzung das Bild des Ulcus serpens einen etwas abweichenden Charakter gewinnen kann.

\section{Fall VI.}

Daniel Rang, 49 Jahre alt, Steinklopfer, erlitt auf seinem linken Auge eine Verletzung durch einen kleinen Steinsplitter, der durch die Drahtbrille flog. Am ersten Tage relativ wenig Beschwerden, doch schon in der Nacht stellten sich lebhafte Schmerzen und dann zunehmende Entzïndung ein. Frïher hat Patient angeblich schon wiederholt an conjunctivalen Beschwerden auf beiden Augen gelitten, auch ist zur Zeit rechts ein geringer Grad von chronischer Conjunctivitis vorhanden.

Status praesens: Links centrale quere Hornhautwunde circa $3 \mathrm{~mm}$ lang mit unnegelmässigen Rändern etwa bis in die Mitte der Fornhant dringend. Die temporale Hälfte der Wunde durchscheinend, die nasale dagegen in der Tiefe eitrig infiltrirt. Es hat sich hier bereits eine kleine rundliche Ulceration gebildet, nach unten mit gelblichem oberflächlichem Rande, doch liegt nach oben die eitrige Infiltration hauptsächlich in der Tiefe im Parenchym der Hornhaut und besteht hier aus zwei confluirenden gelben Infiltraten. Eine gewisse Aehnlichkeit mit Ulcus serpens besteht wohl, doch ist der Fall nicht ganz typisch, der Process greift im Verhältniss zu seiner Grösse auffallend in die Tiefe (doch conf. die Verletzung). Die übrige Cornea ist diffus rauchig getrübt, ziemlich grosses Hypopyon, Iritis.

Am nächsten Tage schon gleicht das Bild dem typischen Uleus corneae serpens, indem es mit einem oberffächlich gelblich infiltrirtem Rande nach unten fortschreitet.

Die bakteriologisehe Untersuchung des Krankheitsheerdes ergiebt Reinkulturen von Kapseldiplocokken (Pneumocokken) sowohl im Deckglas als auf Blutserum und Agarculturen.

Fall VII.

11. IX. 96. August Hübner, 46 Jahre alt, leidet angeblich seit acht Tagen an einer Entzündung seines rechten Auges. 
Ein Thränen des rechten Auges soll schon seit längerer Zeit vòrhanden gewesen sein. Am 3. IX. 96 Verletzung des rechten Auges dureh Fichtenzweig.

Status praesens: Fis besteht eine Stenose des Ductus nasolacrymalis, jedoch bei Druck auf den Thränensack nur relativ wenig schleimig eitriges Secret ausdrüekbar. - Im Centrum der rechten Hornhaut, von dort weiter nach unten reichend ein rundliches gelbeitriges tiefes Infiltrat von $5 \mathrm{~mm}$ Durchmesser, flach uleerirt und gleichmässig gelb infiltrirt, bisher nicht von ausgesprochenem serpiginösem Charakter. Hypopyon von ea. $3 \mathrm{~mm}$ Höhe, starke Iritis.

Die bakteriologische Untersuchung des Krankheitsheerdes ergiebt im Deckglas sowohl als auf den Culturen massenhafte Kapseldiplocokken (Pneumocokken) in Reincultur. Also hier, trotz zunächst nicht ausgesprochenen serpiginösen Charakters des eiterigen Hornhautprocesses, doch lediglich Pneumocokkenbefund.

Wegen der Tiefe des Processes zunächst antiseptische Behandlung ohne Galvanokaustik. Zwei Tage später wegen Fortschreiten des Processes quere Durchschneidung nach Saemiseh mit späterer wiederholter Wiedereröffnung der Wunde. Im Anschluss daran Besserung, doch bildet sich jetzt, während der Process im Centrum sich lichtet, am unteren Rande eine typisch serpiginöse Randinfiltration aus, welche sodann durch zweimalige Galvanokaustik coupirt werden kann. Heilung unter Bildung eines grossen Leucoma corneae adhaerens, Iridektomie nach oben. (Also in den s̀päteren Stadien des eitrigen Hornhautprocesses zeigte sich auch hier noch ein serpiginöser Charakter nach einer Richtung bin).

Diesen 33 Fällen mit typischen Pneumocokkenbefund gegenüber steht nun ein Fall, in welchem wir dieselben nicht haben cultiviren können, während reichlich die Diplabacillen wuchsen, wie sie von Morax, Axenfeld und Peters bei chronischer Blepharoconjunctivitis gefunden worden sind. Da dieser Fall bisher der einzige ist, wo wir die Eiterung nicht auf Pneumocokken zurückführen dürfen, so sei derselbe hier in Kürze mitgetheilt.

Mann von ca. 40 Jahren. Links oberflächliche Fingernagelverletzung unten aussen nahe dem Hornhautrand, die centralwärts gelegenen Theile des Defeets graugelblich infiltrirt. Diese Stelle ist von der Peripherie her etwas unterminirt. Die Deck- 
glsisuntersuchung der infiltrirten Stelle ergiebt in mässiger Zahl Doppeibakterien, meist ausgesprochen bacillär und ziemlich gross, nur einzelne kleiner und mit der Kapsel. Eine Gram'sche Färbung liess sich wegen Mangels weiteren Materials nicht vornehmen. Da der Befund nicht so war, wie bei Ule. serp. incip., wurde zunächst conservativ behandelt.

Darauf am nächsten Tage Geschwür gereinigt, Auge blasser.

Nach zwei weiteren Tagen der Besserung plötzliches Recidiv, indem der centralwärts gelegene Rand der bereits facettirten Stelle ziemlich breit eiterig erscheint. Es besteht jetzt entschiedene Aehnlichkeit mit Uleus serpens; kleines Hypopyon, Iritis.

Im Deckglas wieder vorwiegend auffallend grosse diplobacilläre Formen, einzelne den Pneumocokken ähnliche Gebilde mit Kapsel. Galvanokaustik, nach Anlage von 1 Blutserum.

Am nächsten Tage auf der Cultur ca. 40 flach eingesunkene glasige Stellen im Serum, typische Diplobacillen (ef. Centralblatt für Bakteriologie 1897, Nr. 1). Keine deutlichen andersartigen Mikroorganismen.

Wir haben also in diesem Falle die Diplobacillen als die Eitererreger anzusehen, wie sie Morax bereits in einem atypischen kleinen Infiltrat gefunden hat. $\mathrm{Ob}$ neben ihnen in geringerer Zahl Pneumocokken vorhanden waren, die auf der Cultur nicht gegen die Bacillen aufkamen, möchten wir unentschieden lassen; ebenso wissen wir.nicht, ob bei weiterem Verlauf die eben erst beginnende Eiterung einen typisch serpiginösen Charakter behalten hätte. - Eine gewisse Aehnlichkeit bestand aber jedenfalls. Wir möchten aber nicht verfehlen, nochmals darauf hinzuweisen, dass. dieser Fall unter 69 im Ganzen von uns untersuchten Ulcera serpentia der einzige seiner Art gewesen ist.

\section{Fälle von atypischer Hypopyonkeratitis mit ihren bakteriologischen Befunden.}

Dreizehn derartige Fälle kamen zur Untersuchung. In Bezug auf die Definition dieser Fälle dem typischen „Ulcus serpens" gegenüber sei hier auf unsere früheren Ausführungen nochmals verwiesen. Es handelt sich hier um Fälle, welche 
Weitere Beiträge z. Bakteriologie d. Keratitis des Menschen etc. 185

nicht ein derartiges typisches Weiterkriechen des eiterigen Processes in die Umgebung, namentlich in den oberflächlichen Schichten der Hornhaut, zeigen, wie das Ulcus serpens, sondern wo eiterige Infiltrate mit verschiedener Localisation, mit ulcerösen und in die Tiefe greifendem Zerfall von krater- und muldenförmigem Aussehen, eventuell zur Perforation neigend $u$. s. w. vorhanden sind.

Nach ihrem bakteriologischen Befunde sondern sich die Fälle in folgende Gruppen:

1. Nur Pneumocokken . . . . . . . $2 \mathrm{Mal}$

2. Pneumocokken mit reichlichen anderen Mikroorganismen . . . . $3 \mathrm{MaI}$

(pyogene Bacillen, Staphylocokken, Xerosebacillen).

3. Keine Pneumocokken, nur andere Mikroorganismen . . . . . . . . $8 \mathrm{Mal}$

(Bacillen, Streptocokken, Staphylocokken).

Die Complicationen in diesen 13 Fällen gestalten sich folgendermaassen:

Trachom . . . . . . . . . . . in 4 Fällen

Blepharo-Conjunctivitis . . . . . . in 2 Fällen

Schwellungskatarrh der Conjunctiva . . in 1 Fall

Dacryoblennorhoe . . . . . . . . in 1 Fall.

Wir sehen hier zunächst, dass bei diesen Fällen eine Conjunctivalerkrankung am häufigsten und relativ oft als Complikation vorliegt, während ein Thränenleiden nur einmal vorkam und zwar bei einem Fall, wo in dem Hornhautprocess nur Pneumocokken nachgewiesen werden konnten. Es zeigt sich die Art der Complicationen jedenfalls bei diesen Fällen wesentlich anders als bei dem eigentlichen Ulcus corneae serpens, wo in über ein Drittel der Fälle ein Thränenleiden vorhanden war und primäre Conjunctivalerkrankungen nur relativ selten vorkamen.

Auch aus dieser Reihe sollen nur ganz vereinzelte Fälle angeführt werden, die ein besonderes Interesse bieten. Zu- 
nächst die beiden Fälle, wo Pneumocokken in Reincultur gefunden wurden:

\section{Fall VIII.}

13. II. 96. Wilhelm Kamm, 44 Jahre alt, war bis dahin gesund. Am 8. II. 96 flog dem Patienten ein abspringender Nagel gegen das rechte Auge. Es traten sofort heftige Sehmerzen ein, und Patient ging zum Arzt, der einen „kleinen gelben Flecken oben in der Hornhaut" feststellte. Trotz Atropin und BorsäureUmsehläge starke Verschlimmerung.

Status praesens: Am oberen Rande der Cornea, bis tief in den Limbus reichend, intensiv eiterig infiltrirte linsengrosse Stelle, die ganze Dicke der Cornea einnehmend, nach unten flach convex begrenzt. In ihrer oberen Hälfte ist die Stelle tief exulcerirt in Gestalt einer queren Furche, deren Centrum bereits eine kleine sehwärzliche Keratocele zeigt. Die untere Hälfte des Infiltrates ist noch nicht zerfallen, etwas gebläht, scheint aber von der defecten Stelle aus unterminirt, da beim Entnehmen des Impfmaterials sich die obersten Schichten leicht verschieben lassen. Uebrige Cornea rauchig getrübt, unten in der vorderen Kammer ein schmales Hypopyon, starke pericorneale Injection, etwas Chemosis. An der exulcerirten Stelle haftet ziemlich massiges eiteriges Secret.

Am 13. II. 96 ist die eiterige Infiltration erheblich fortgeschritten nach unten, subepithelial, die Keratocele hat sich vergrössert. Paracenthese der vorderen Kammer. Trotzdem schreitet die eiterige Infiltration durch die ganze Dicke der Cornea stetig nach unten fort in den nächsten Tagen unter Entwicklung eines grossen Irisprolapses.

Am 19. II. 96 ist die ganze Cornea intensiv gelb eiterig infiltrirt, das obere Drittel völlig ulcerös zerfallen, stark geblähter Irisprolapsus. Die unteren infiltrirten Theile der Cornea sind noch mit Epithel bedeckt.

Am 20. II. 96 Exenteratio bulbi.

Bakteriologische Untersuchung. Zu zwei versehiedenen Malen Entnahme von Impfmaterial. Beide Male ergiebt die Untersuchung im Deckglaspräparat sowohl als auf den Nährböden (Blutserum, Glycerin, Agar), Reinculturen des Pneumocokkus. Es wachsen auf den verschiedenen Röhrchen im Brïtofen dichte Rasen kleiner tröpfenförmiger Glasculturen. Dieselben bestehen aus länglichen Diplocokken und kurzen Ketten, die sich 
nach Gram gut färben. In Bouillon bilden dieselben eine zarte Trübung, die nach einigen Stehen einen Bodensatz bildet.

Von der nekrotischen Hornhaut wird unmittelbar nach der Exenteration ein Stückchen in die Hornhauttasche eines Kaninchens verimpft. Es entsteht eine Hypopyonkeratitis mittleren Grades, ohne Perforation spontan heilend. (Also hier klinisch nicht das typische Bild des Uleus corneae serpens und trotzdem Reincultur von Pneumocokken.)

\section{Fall IX.}

Frau Kaufimann, 67 Jahre alt, stellt sich mit einem eiterigen Hornhautprocess in der Klinik vor, der nicht dem typischen Bilde des Ulcus corneae serpens entspricht. Es besteht ein linsengrosses, geblähtes, rundes, gleichmässig gelbes Infiltrat im Centrum der linken Hornhaut, über demselben ist die Epitheldecke noch erhalten, lässt sich aber leicht abheben. Es ist mehr das Bild eines interstitiellen Abscesses. Die übrige Cornea ist rauchig getrübt, starke Iritis und grosses Hypopyon.

Im Deckglaspräparat sowohl als auf den Culturen finden sich nur Pneumocokken mit ihren typischen morphologischen Eigenschaften, färben sich nach Gram. (Also dieses Mal das Bild einer atypischen Hypopyonkeratitis und trotzdem Pneumocokkenbefund in Reincultur.)

Diese beiden Beobachtungen zeigen uns also, dass die Pneumocokken-Affection der Cornea gelegentlich nicht unter dem typischen Bilde des Ulcus corneae serpens zu verlaufen braucht; in beiden Fällen handelte es sich um tiefgreifende eiterige Infiltrationsprocesse der Cornea, namentlich in dem ersten Fall mit einer ausgesprochenen Tendenz zur Fortschreiten. Nun in diesem Falle, glauben wir, dürfte die Erklärung des vom typischen Uleus serpens abweichenden Bildes keine Schwierigkeiten haben. Ein spitzer Nagel ist ganz tief in die Randparthieen der Hornhaut eingedrungen und hat offenbar so eine Infection der Cornea in deren ganzer Dicke zu Stande gebracht. Unter den Umständen war kein oberflächliches serpiginöses Hornhautgeschwïr zu erwarten, sondern bei dem progressivem Charakter des Leidens eine eiterige Infiltration durch die ganze Dicke der Cornea. 
In dem zweiten Fall ist es bei etwas unzureichender Anamnese schwer eine hinreichende Erklärung zu geben, jedenfalls zeigen die beiden Fälle, dass gelegentlich die Pneumocokken in der menschlichen Cornea einen eiterigen Process hervorrufen können, der von dem Bilde des typischen Ulcus corneae serpens abweicht. Nach unseren bisherigen Untersuchungsresultaten aber muss ein solches Vorkommen als relativ selten angesehen werden.

Hieran schliesst sich eine von den drei Krankengeschichten, wo bei atypischer Hypopyonkeratitis neben anderen Mikroorganismen ebenfalls noch Pneumocokken gefunden wurden. Diese Beobachtung betrifft ein 10jähriges Kind. Es ist besonders hervorzuheben, wie selten in unseren Untersuchungsreihen von eiteriger Keratitis des Menschen das jugendliche Lebensalter vertreten ist, ja ein typisches Ulcus corneae serpens bei einem Kinde findet sich unter unseren ganzen Fällen auch nicht ein einziges Mal.

\section{Fall X.}

Am 13. IV. 96 wird Elisabeth Schwalm, 10 Jahre alt, mit einer atypisehen Hypopyonkeratitis in die Marburger UniversitätsAugenklinik aufgenommen. Es besteht auf der linken Hornhaut ein rundes, glattrandiges, ea. 2,5 mm breites, muldenförmiges Geschwür mit gelb infiltrirtem Grunde, während die Ränder nicht infiltrirt sind. Die übrige Cornea ist rauchig getrübt und um das Uleus herum ein stärkerer grauer Hof. Kleines gellbweisses Hypopyon.

Die bakteriologische Untersuchung im Deckglas und auf den verschiedenen Nährböden ergiebt bei wiederholten Abimpfungen zahlreiche gelbweisse runde saftige Colonieen (Staphylococeus citreus). Viel zahlreicher jedoch finden sich kleine feine punktförmige Colonieen, die als aus Pneumocokken bestehend angesprochen werden müssen. Dieselben bilden vielfach im hängenden Tropfen (Reincultur im Condenswasser von Blutserum) kürzere, gelegentlich auch längere Ketten. Fürben sich nach Gram, wachsen nicht im Gelatinestich. - In die Kaninehen-Hornhaut verimpft, erregen sie eine mässige entzündliche Reaction, der Process bildet sich spontan zurück.

Das Hornhautulens bei dem Kinde zeigt auch im weiteren Verlaufe keine Neigung zu serpiginöser Ausbreitung nach einer 
Richtung, obwohl das Hypopyon und die Infiltration des Geschwürsgrundes zunächst noch etwas zunimmt. Es erfolgt schliesslich Heilung ohne Perforation unter Anwendung von Galvanokaustik und desinficirender Behandlung des Uleus. (Also eine atypisehe Hypopyonkeratitis mit dem bakteriologisehen Befunde vorwiegend Pneumocokken gleichzeitig mit Staphylococcus citreus.)

In den anderen beiden Fällen dieser Gruppe atypischer Hypopyonkeratitis mit Pneumocokkenbefund neben anderen Mikroorganismen handelt es sich um ältere Personen mit mehr randständigem Sitz der relativ gutartigen und bei conservativer Behandlung zurückgehenden Affection; der eine von ihnen ist mit Trachom und Keratitis pannosa complicirt; in dieser vascularisirten Hornhaut ist ein atypischer Verlauf nicht zu verwundern; in dem anderen waren die Pneumocokken den anderen Mikroorganismen gegenüber (Bacillen und Xerosebacillen) nur in relativ geringer Anzahl vorhanden.

Dieser mehr randständige Sitz des Krankheitsheerdes gilt durchweg auch für die folgende Gruppe von acht Fällen atypischer Hypopyonkeratitis ohne Pneumocokken, wohl aber mit dem Befunde von anderen Mikroorganismen. Diese Fälle waren sämmtlich bis auf einen mit Conjunctivalerkrankungen complicirt $(3 \mathrm{Mal}$ Trachom, $1 \mathrm{Mal}$ Conjunctivitis ehronica und 1 Mal Schwellungskatarrh der Conjunctiva). $3 \mathrm{Mal}$ wurden Streptocokken allein, $2 \mathrm{Mal}$ Staphylocokken allein und $1 \mathrm{Mal}$ Streptocokken und Staphylocokken zusammen als Krankheitserreger nachgewiesen. Einmal war der Befund negativ, in dem sechsten Fall, der nicht mit einer Conjunctivalerkrankung complicirt war, fanden sich pyogene Bacillen in Reincultur. Die Beobachtung ist folgende.

Fall XI.

Am 17. IV. 96 wird Johann Muth, 54 Jahre alt, in die Marburger Klinik aufgenommen. Es besteht links seit drei Tagen ein kleines gelbliches, nicht exulcerirtes Hornhautinfiltrat mit kleinem flüssigen weissgelben Hypopyon in der vorderen Kammer 
mässige Iritis. Der Process hat sich am nächsten Tage noch etwas verschlimmert und haben sich in der Nachbarschaft des ersten grösseren Heerdes noch zwei kleinere gelbe Infiltrate gebildet, ebenfalls subepithelial. Das Hypopyon noch gewachsen. Von einer Verletzung als ätiologisches Moment wird nichts angegeben.

Die bakteriologische Untersuchung: In Deckglas von aus dem grösseren Infiltrat entnommenen Material finden sich zwischen den spärlichen Eiterzellen und dem verriebenen Schlein- resp. Eiweissfäden zahlreiche plumpe Bacillen, zum Theil zu zweien und Doppelcokken ähnlich, meist aber einfach, mit abgerundeten Ecken, zum Theil mit Polfärbung, geradlinig. Länge durehschnittlich $2 \mu$, Breite $1 \mu$ (in Wasser), doch vielfach anch kürzer, manche oval. Nirgends Kapseln, keine Phagocyten.

Auf Glycerin-Agar sind keine Culturen angegangen, dagegen auf Blutserum Reineulturen stecknadelkopfgrosser, flacher, weisslicher, sehr feuchter Colonieen, die schnell zu einem durchseheinend rahmigen Belage confluiren. Diese Colonieen bestehen aus Bacillen; Länge ca. $2 \mu$, Breite etwas über $1 \mu$, Enden leicht abgestumpft und etwas verdickt. Die Mikroorganismen liegen oft zu zwei hinter einander, doch fehlen längere Verbände, zwei hinter einander liegende Bacillen erscheinen oft als ein grosser Bacillus. Färben sich nach Gram. Im Condenswasser des Blutserums sind sie massenhaft vorhanden, obwohl makroskopisch fast gar keine Trübung sichtbar ist. Im hängenden Tropfen keine Eigenbewegungen, im Uebrigen dieselben Formen, vielfach in kleinen unregelmässigen Häufchen, auch einzelne längere Verbände, bei denen jedoch die Einzelindividuen noch deutlich sind, sehr viele Doppelformen. - Wachsen nicht im Gelatinestich. Blutserum wird umsehrieben verflüssigt. Bouilloncultur zeigt anfangs zarte graue diffuse Trübung, später dieke Trübung mit etwas fadenziehendem Bodensatz. Intraperitoneale Injection einer Bouillon bei einem Meerschweinchen bleibt ohne Wirkung.

In die Hornhauttasehe eines Kaninchens verimpft, erregt der Mikroorganismus eine erhebliche weissgelbliche Infiltration an der Impfstelle, die jedoch auch im weiteren Verlauf wenig Neigung: zu ulcerösem Zerfall hat. Jedenfalls erweist sich der Bacillus für die Kaninchen als erheblich local virulent.

Es handelt sich somit um einen bisher nicht beschriebenen für die Kaninchen- und Mensehenhornhaut pathogenen Bacillus, der mit dem Diplobacillen der Conjunctivitis chronica zwar in der Form und in dem Wachsthum auf Serum einige Aehnlichkeit hat, aber durch die Färbbarkeit nach Gram, sein Wachs- 
Weitere Beiträge z. Balteriologie d. Keratitis des Menschen etc. 191

thum in Bouillon und seine Pathogenität sich von demselben wesentlich unterscheidet.

III. 3 Fälle von Xeroph thalmus mit rapider Keratomalacie (bei Kindern der ersten Monate).

Bakteriologischer Befund: Massenhafte Culturen von Streptococcus pyogenes (wachsen im Gelatinestich u. s. w.), mässig reichliche Pseudodiphtheriebacillen.

\section{Von scrophulöser oberflächlicher Keratitis}

wurden fünf Fälle untersucht und zwar 3 Mal Keratitis fascicularis und $2 \mathrm{Mal}$ geblähte Infiltrate der Cornea. Die Fälle von Keratitis fascicularis zeigten $1 \mathrm{Mal}$ Xerosebacillen, $1 \mathrm{Mal}$ einzelne Bacillen und Staphylocokken und $1 \mathrm{Mal}$ nur einige Staphylocokken, bei den beiden Hornhautinfiltraten wurde $1 \mathrm{Mal}$ nichts gefunden, das andere Mal Bacillen in spärlicher Anzahl. Das Deckglas von dem direct entnommenen Material zeigt in diesem Fall keine Mikroorganismen, dagegen zeigen sich auf der Blutserumcultur einige etwas eingesunkene graue Colonieen, welche aus grossen verschieden langen Bacillen bestehen. Im hängenden Tropfen keine Eigenbewegungen. In Bouillon bilden sich eine diffuse durchscheinende Trübung mit reichlichem fadenziehendem Bodensatz, vielfach bilden sie lange Schleimfäden. - Auf Gelatine und Glycerin-Agar sind sie nicht gewachsen.

Da der Befund im Deckglas fehlt, so handelt es sich hier wohl um einen zufälligen Befund und nicht um einen specifischeu Krankheitserreger.

\section{Von Keratitis dendritica}

kamen sieben Fälle zur Untersuchung. Hiervon boten zwei Patienten nur den Befund der Xerosebacillen, zwei andere den der Xerosebacillen gleichzeitig mit vereinzelten Staphylocokken, ein Fall den Befund von Staphylococcus aureus 
und albus (hier war gleichzeitig ein Hypopyon in der vorderen Kammer), und $1 \mathrm{Mal}$ war der Befund negativ.

Trotz des relativ häufigen. Befundes der Xerosebacillen sind wir, auch mit Rücksicht auf die Impfresultate für die Kaninchen-Cornea, nicht in der Lage den Befund mit dem Krankheitsprocess in einen ursächlichen Zusammenhang zu bringen, sondern halten diesen Bacillus für einen zufälligen Ansiedler bei dieser gewöhnlich schon etwas länger bestehenden Hornhautaffection. In dem einen Fall, wo es zu einem eiterigen Charakter des Processes mit Hypopyonbildung gekommen war, mit dem bakteriologischen Befunde zahlreicher Staphylocokken, möchten wir eine Secundärinfection annehmen. Jedenfalls ist es bisher nicht gelungen, so klinisch eigenartig auch die Keratitis dendritica verläuft, einen specifischen Mikroorganismus als Krankheitserreger für diesen Process nachzuweisen.

\section{Ein Fall von Ulcus rodens.}

(Derselbe ist genauer in Dissertation von Frank-Marburg, Beiträge zu den Erkrankungen der Hornhaut u. s. w. 1896 mitgetheilt worden. Bakteriologischer Befund negativ.)

\section{Zwei Fälle von Keratitis pannosa bei Trachom.}

1 Mal Xerosebacillen, 1 Mal Befund negativ.

VIII. Ein Fall von Keratitis parechymatosa bei Lues congenita.

Ganz im Beginn des Processes wird Material von den erkrankten Randparthieen der Cornea entnommen, Befund negativ.

IX. Zwei Fälle von Hornhautveränderungen

bei Frühjahrskatarrh.

Bakteriologischer Befund negativ. 


\section{Fin Fall von Keratmycosis aspergillina wiederum Aspergillus fumigatus.}

Wir haben somit auch in dieser Untersuchungsreihe wiederum einen Fall von Schimmelkeratitis zu verzeichnen. Die Beobachtung ist folgende.

Am 1. VII. 96 stellt sich der 14jährige Johannes Klee in der Marburger Augenklinik vor. Seit fünf Tagen verspürt er ein Drücken in seinem rechten Auge. Eine Ursache dafür ist ihm nicht bekannt, er hat auf dem Lande gearbeitet, aber von einer Yerletzung weiss er nichts.

Status praesens: Sonst gesund, das linke Auge ist normal. Das rechte Auge zeigt eine pericorneale Injection, aussen auch stärkere Röthung der Conjunctiva bulbi, besonders am Sklerallimbus. Von diesem $2-3 \mathrm{~mm}$ entfernt liegt in der durchsichtigen Hornhaut eine rundliche, ea. $2 \mathrm{~mm}$ im Durchmesser betragende graugelbliche Trübung von etwas erhabener Oberfläche, bei oberflächlicher Betrachtung einer Hornhautphlyktäne sehr ähnlich, zumal vom Limbus aus mehrere kleine Gefässe bis in die Nähe des Heerdes ziehen, doch erreichen dieselben die Trübung nicht ganz. Bei genauerer Betrachtung fällt auf, dass die gelbliche, flach convexe kleine Masse in einer Art von Mulde sitzt und gegen die Umgebung durch eine kleine rinnenförmige Vertiefung sich allseitig abgrenzt, so dass sie wie ein kleiner flacher Knopf oder wie ein ganz kleiner Pilz der Unterlage aufliegt. Unter der Loupe lässt sich erkennen, dass am oberen Rande diese kleine, so auffallend demarkirte Scheibe etwas bräunlich aussieht. Nach alledem lag die Vermuthung nahe, dass es sich um einen flachen, in Exsudat eingehüllten Fremdkörper handeln könne.

Nach Cocain-Einträufelung liess sich die ganze gelbliche, auffallend consistente Masse in toto ohne grosse Mühe abheben, so dass eine kleine muldenförmige Einsenkung in der Cornea zurück bleibt, welche graulich getrübt erscheint. Es zeigt sich nun, dass unter der gelblichen Oberfläche in der That ein ea. 1,5 mm langer und $1 \mathrm{~mm}$ breiter braunrother Fremdkörper sitzt. Die denselben überziehende graugelbliche Masse aber ist so fest mit ihm verbunden, dass trotz wiederholten Hinüberfahrens über Blutserum und über Deckgläser sie doch fest mit ihm in Zusammenhang bleibt. Nur durch kräftiges Zerzupfen gelingt es, zur mikroskopischen Untersuchung und zur Uebertragung auf den Nährboden ein Stückchen loszulösen. 
Mikroskopische Untersuchung: Ungefärbt in Kochsalzlösung $(0,75 \%)$ zeigt sich nun der ganze Ueberzug aus einem dichten Mycel dichotomisch verzweigter Schimmelpilzfäden zusammengesetzt. Keine Fructification.

Der braune Fremdkörper lässt bei schwacher Vergrösserung erkennen, dass er eine Längsstreifung und Felderung zeigt. Herr Prof. Arthur Meyer, Director des botanischen Institutes, hatte die Güte auf unsere Bitte eine genauere Untersuchung des Fremdkörpers vorzunehmen und und stellte fest, dass es sich zweifellos um einen Pflanzentheil handelte, da auf Zusatz von Chlorzinkjodlösung zu einem kleinen abgetrennten Stückehen ausgesprochene Blaufärbung eintritt (Cellulose, wahrscheinlich auch Stärke). Woher dieser Pflanzentheil stanmt, liess sich wegen starker Quellung und Veränderung des Gewebes nicht sicher feststellen. Es könnte z. B. von einem Schachtelhalm oder irgend einer Graminee etc. herrühren. Das Hauptstück des Fremdkörpers mit daran haftendem Mycel wird für einige Stunden in $10 \%$ Formol und dann in Alkohol gebracht. Nach zwei Tagen Einbettung in Paraffin und dann Zerlegung in eine Schnittserie.

Mikroskopisch lässt sich Folgendes feststellen (s. hierzu Tafel VII): Auf der unteren Seite des Schnittes findet sich der Fremdkörper auf dem Durchschnitt. Derselbe ist von bräunlicher Farbe und von gefeldertem Bau und erweist sich, wie oben ausgeführt als Decke eines Pflanzentheiles. An diesen Fremdkörper legt sich der dicke Schimmelpilzrasen, bestehend aus dicht verflochtenen Mycelfäden. Der Zusammenhang dieses Rasens mit dem Fremdkörper ist offenhar artificiell bei den verschiedenen Manipulationen etwas gelockert worden, und so hängt er gleichsam durch einen Stiel (fibrinhaltige Exsudatmassen) nur noch mit dem Fremdkörper zusammen. In den Maschen dieser Exsudatschicht liegen zahlreiche Bacillen (Xerosebacillen), und daran schliesst sich dann der Schimmelrasen. Die Färbung der Mikroorganismen und vielfach auch der Mycelfäden gelingt sehr gut nach der Weigertschen Methode. Fructificationsorgane sind in diesem Mycelrasen nicht nachweisbar.

Die kulturelle Untersuchung der frisch gewonnenen Masse auf Blutserum ergiebt bereits am folgenden Tage einen grösseren kreisrunden Schimmelpilzheerd, der peripher aus zarten, radiären, weissen Fäden besteht und ein etwas erhabenes, leicht meergrünes Centrum hat. Diese grünliche Farbe nimmt bis zum Abend beträchtlich zu und wird etwas dunkler. Die ganze Oberfläche der Schimmelcolonie ist durch senkrecht aufstrebende Fäd- 
chen sammetartig, doch erheben sich diese Fäden nur wenig, höchstens $0,5-1 \mathrm{~mm}$.

Mikroskopisch: Reichliche Fruetification, die Fruchtträger sind unverzweigt und gehen direct in das keulenförmige Köpechen über, auf dem radiär die flaschenförmigen Sterigmen anfsitzen. Letztere tragen an der Spitze die Sporen. Nach der weiteren Entwickelung der Culturen handelt es sich zweifellos um Aspergillus fumigatus. Der Schimmelrasen nimmt in den späteren Stadien ein tief rauchgraues Ausehen an.

Für die Kaninchenhornhaut erweist sich der Schimmelpilz pathogen bei Impfung in einer Hornhauttasche und erzeugt einen charakteristischen eiterigen Hornhautprocess, wie wir ihn in unserem fiüheren Falle bei der Impfung der Kaninehenhornhaut auch erhielten.

Da wo anfangs mit dem frischen Material über den Nährboden gewischt wrrde, aber nur etwas anhaftendes Secret übertragen worden war, wuchsen ausserdem eine kleine Anzahl von Staphylocokken-Colonieen und in grösserer Anzahl Colonieen von Xerosebacillen. Diese Mikroorganismen haben offenbar nichts mit der Entstehung des Krankheitsprocesses zu thun.

Epikrise: Wir wollen hier nicht wieder auf die Literatur der Schimmelkeratitis des Menschen eingehen, die wir in unserer früheren Beobachtung kurz aufführten und die auch jetzt noch immer als eine sehr spärliche zu bezeichnen ist. Hinzugekommen ist inzwischen zu den früheren Beobachtungen noch die von Schirmer (v. Graefe's Archiv f. Ophthalm. XLII. 1. „Ein Fall von Schimmellkeratitis" 1896), der Gelegenheit hatte einen ganzen Bulbus mikroskopisch zu untersuchen, an dem eine Schimmelkeratitis intra vitam bestanden hatte (14jähriger Knabe), es war hier zu einem Hineinwuchern der Schimmelpilze auch in die tiefern Theile des Auges gekommen, nachdem die Membrana Descemetii perforirt war. Eine genauere Bestimmung des Schimmelpilzes durch die Cultur konnte nicht vorgenommen werden.

Unsere jetzige Beobachtung ist jedenfalls diejenige, in der der Verlauf sich am günstigsten und wenig charakteristisch gestaltete. Patient wurde nur poliklinisch behandelt und nach Entfernung des mit dem Schimmelrasen über- 
zogenen Fremdkörpers aus der Hornhaut heilte der Process in relativ kurzer Zeit unter Hinterlassung eines mässigen randständigen Leukom's und ohne Perforation. Es war hier auch offenbar zu einem tieferen Hineinwuchern der Schimmelpilze in die Corneasubstanz gar nicht gekommen, sondern nur eine mässig tiefe Delle war in der Hornhaut entstanden, aus welcher sich Fremdkörper mit Pilzrasen glatt herauslösen liess.

Durch die Cultur wurde auch hier wieder Aspergillus fumigatus festgestellt und so sind bisher alle Fälle (Leber, Fuchs und unsere zwei), in denen der Schimmelpilz bestimmt werden konnte, als durch Aspergillus fumigatus verursacht anzusehen. Es wäre ja sehr wohl denkbar, dass auch andere Schimmelpilze, welche bei höherer Temperatur gedeihen and sich bei der experimentellen Untersuchung als pathogen für das lebende Gewebe erwiesen haben, wie z.B. Mucor rhizopodiformis und corymbifer (Lichtheim) oder Aspergillus flavescens allenfalls auch niger, beim Menschen eine Schimmelkeratitis hervorrufen könnten, jedoch scheinen derartige Fälle bisher nicht beobachtet worden zu sein.

Auch dieser Fall von Schimmelkeratitis ist also, wie alle bisherigen Beobachtungen, nicht unter dem Bilde des Ulcus serpens verlaufen; die entgegengesetzte Angabe von Bach (v. Graefe's Archiv f. Ophthalm. XI. 1. S. 73, 1895) ist nicht zutreffend.

\section{Resümirende Schlussbemerkungen.}

Wenden wir uns jetzt auf Grundlage der bei dieser neuen Untersuchungsreihe gewonnenen Resultate der Beantwortung der im Eingang unserer Arbeit aufgeworfenen Fragen zu:

Es zeigt sich zunächst, dass in fast allen Fällen, wo die klinische Diagnose des typischen Ulcus corneae serpens gestellt werden musste, stets der Fraenkel-Weichselbaum'sche Diplococcus (Pneumococcus) gefunden wurde 
und zwar in der bei weitem grösseren Mehrzahl der Fälle in Reincultur, in einer relativ kleinen Anzahl von Fällen vergesellschaftet mit spärlichen anderen Mikroorganismen (wie Staphylocokken und Xerosebacillen). Dieses Ergebniss ist somit noch significanter, wie in unserer ersten Untersuchungsreihe, wo in ganz vereinzelten Fällen von Ulcus corneae serpens keine Pneumocokken gefunden wurden. Wir haben schon damals darauf hingewiesen, wie wahrscheinlich die mangelhafte Beschaffenheit des Nährbodens den Grund hierfür bildete. Es bestätigen somit unsere neuen Untersuchungen die früheren Erfahrungen, und müssen wir in den Pneumocokken die eigentlichen Erreger des typischen Ulcus corneae serpens sehen. Nur ein einziges Mal haben wir mit Sicherheit nicht sie, sondern Diplobacillen (Morax, Axenfeld, Peters) gefunden.

Unsere schon damals ausgesprochene Vermuthung, dass gelegentlich die Pneumocokken-Infection der Hornhaut, je nach der Eigenart und Tiefe der Verletzung, Grad der Virulenz u. s. w., auch unter einem anderen klinischen Bilde (z. B. dem der atypischen Hypopyonkeratitis) verlaufen könne, findet in unserer neuen Untersuchungsreihe in einzelnen Fällen Bestätigung. So sind Fall VII und VIII Kranke mit atypischer Hypopyonkeratitis und Reinculturen von Pnewmocokken. In Fall VII ist es offenbar die tief eindringende Verletzung der Cornea durch einen abspringenden Nagel, welche zu einer eitrigen Infiltration durch die ganze Dicke der Hornhaut Veranlassung giebt, bei dem typischen Ulcus corneae serpens handelt es sich in der Regel um mehr oberflächliche Verletzungen. Auch in drei weiteren Fällen von atypischer Hypopyonkeratitis wurden noch Pneumocokken gefunden, aber vergesellschaftet mit anderen Mikroorganismen (Bacillen, Staphylocokken, Xerosebacillen), welche zum Theil offenbar praevalirten. Es liegt die Sache demnach so, dass beim typischen Ulcus corneae serpens fast immer die Pneumocokken gefunden 
werden und offenbar die Krankheitserreger sind, dass sie jedoch, wenn auch relatlv selten, bei der atypischen Hypopyonkeratitis ebenfalls vorkommen, hier aber oft vergesellschaftet mit anderen Mikroorganismen. Ausserdem ist in dem einen Ealle gleichzeitig ein Pannus trachomatosus dagewesen und es ist wohl verständlich, dass in einer vascularisirten Hornhaut eine Infection etwas anders verläuft als in einer gefässlosen, wie ja auch am Hornhautrande der Verlauf eines Geschwüres sich günstiger zu gestalten pflegt, worauf mit Recht Bach Werth legt. Bach und Neumann beschreiben ebenfalls zwei nicht ganz typische Pneumocokkeninfectionen.

Viermal gelang es uns, das Ulcus corneae serpens im allerersten Stadium zur bakteriologischen Untersuchung zu bekommen, und zwar zu einer Zeit, wo klinisch nur erst ein Infiltrat eventuell mit ulcerösen Zerfall vorhanden war, ohne sichtbar fortschreitenden serpiginösen Charakter und wo erst in den nächsten Tagen sich das typische Bild entwickelte. Einen ebensolchen Fall beschreiben Bach und Neumann. Stets fanden sich massenhafte Pneumocokken im entnommenen Material. Bei diesem bakteriologischen Befunde hat man durchweg auf ein rasches Fortschreiten des Processes, auf die Ausbildung eines Ulcus comeae serpens zu rechnen, und es erhellt daraus, dass ein reichlicher Pneumocokkenbefund im Infectionsheerd zu sofortigem energischem therapeutischem Vorgehen mahnt, am besten durch Anwendung der Galvanokaustik, zumal wenn die Patienten nicht in die Klinik aufgenommen werden.

Die Thatsache, dass Kinder offenbar sehr selten von einem typischen Ulcus corneae serpens befallen werden, tritt auch bei dieser neuen Untersuchungsreihe ausserordentlich markant zu Tage. Unter den eigentlichen typischen Ulcus serpens-Fällen befindet sich überhaupt kein Kind, unter den Fällen von atypischer Hypopyonkeratitis ein 10jähriges Mädchen mit Pneumocokken neben Staphylo- 
cokken. Wir müssen glauben, dass die Hornhaut im jugendlichen Lebensalter weniger für die Entstehung eines Ulcus corneae serpens prädisponirt ist, ohne dass wir allerdings im Stande sind eine ausreichende Erklärung dafür zu geben.

Wiederholt konnte auf dem Gebiete des Ulcus corneae serpens, welches in über ein Drittel der Fälle mit Thränenleiden complicirt war, constatirt werden, dass es sich bei dem Hornhautprocess um Reinculturen von Pneumocokken handelte, während im Thränensack neben den Pneumocokken auch andere zum Theil pathogene Mikroorganismen gefunden wurden. Diese Thatsache spricht dafür, dass die Pneumocokken bis zu einem gewissen Grade die Fähigkeit besitzen, andere Mikroorganismen neben sich nicht aufkommen zu lassen. Es wäre auch sonst der Umstand schwer verständlich, dass selbst bei längerer Zeit bestehendem Ulcus corneae serpens die Pneumocokken oft noch in Reincultur angetroffen werden.

In einer grösseren Anzahl von Fällen haben wir mit den aus dem Ulcus serpens gewonnenen Reinculturen von Pneumocokken subcutane Impfungen von weissen Mäusen vorgenommen, welche meistens zur Pneumocokken-Septicaemie mit tödtlichem Ausgang und charakteristischem Blutbefund mit Kapseldiplocokken führten.

Einen Fall von Keratomycosis aspergillina fanden wir auch wieder in dieser neuen Untersuchungsreihe, es würde das zusammen mit unserem früheren Falle fast $2 \%$ der eitrigen Keratitis ergeben. Wir glauben nun, dass diese Zahl zu hoch gegriffen sein dürfte, und müssten es als einen besonderen Zufall ansehen, dass unter ca. 100 Fällen 2 Fälle von Schimmelkeratitis sich befanden. Immerhin darf man wohl annehmen, dass die Schimmelkeratitis des Menschen häufiger ist, als man nach den bisherigen sehr spärlichen Mittheilungen in der Literatur geneigt sein könnte anzunehmen, und unsere beiden Beobachtungen zeigen vor Allem, dass auch leichtere Fälle eitriger Keratitis, welche 
ohne Perforation heilen, gelegentlich auf einer SchimmelpilzInvasion in die Hornhaut beruhen können; so weit bisher untersucht werden konnte, handelt es sich scheinbar immer um Aspergillus fumigatus.

Wenn wir noch einen kurzen Blick auf die seit unserer ersten Arbeit uns bekannt gewordenen Mittheilungen uiber eiterige Keratitis des Menschen ${ }^{1}$ ) werfen, so ist zunächst hervorzuheben, dass $\mathrm{K}$ alt die Ulcerationen bei der Blennorrhoe, die bekanntlich die typisch serpiginöse Form nicht zeigen, auf Staphylocokken zurückführt, die er im mikroskopischen Präparat gefunden zu haben berichtet. Die leichten Fälle dieser Art beilen nach seiner Ansicht durch Phagocyten, welche schon bei der Ankunft der Mikroorganismen auf der Bowman'schen Membran dieselben empfangen und vernichten sollen. Wir möchten dem gegenüber nochmals hervorheben, dass für den Pneumococcus die Phagocytose nicht in Proportion zur Gutartigkeit des Processes zu stehen braucht. Die Angaben Kalt's stehen ferner im Widerspruch mit den von $\mathrm{Bach}$ für das Staphylocokkengeschwür der Hornhaut gemachten Angaben.

Es hat ferner Hori in den eiterigen Rändern eines atypischen Geschwürs dichte Reinculturen von Streptocokken gefunden.

Sodann hat Morax aus einem atypischen Infiltrat die zuerst von ihm ${ }^{2}$ ) und dann von Axenfeld ${ }^{5}$ ) beschriebenen Diplobacillen der chronischen Conjunctivitis gezüchtet; für das Thier sind dieselben nicht pathogen, nur für den Monschen. Ueber einen analogen Befund haben wir oben berichtet.

Die von Zirm unter dem Epitheldefect einer beginnenden Keratomalacie beschriebenen dichten Rasen von

1) Cf. das Literaturverzeichniss am Schlusse.

2) Annales de l'institut Pasteur 1896. Juin.

3) Centralblatt für Bakteriologie 1897. Nr. 1. 
Weitere Beiłräge z. Bakteriologie d. Keratitis des Menschen etc. 201.

rundlichen Cokken sind bezüglich ihrer Art nicht näher bestimmt worden.

Nuël (Arch: d'ophthalm. 1896, Dec.) theilt einen eigenthümlichen Fall von heerdförmiger oberflächlicher Keratitis im Anschluss an eine frühere Ammoniak-Anätzung der Cornea mit, wo er massenhafte Cokkenanhäufungen in den Heerden fand. Eine Cultivirung der Mikroorganismen und damit eine genauere Bestimmung derselben konnte nicht vorgenommen werden. $\mathrm{Ob}$ es gerechtfertigt ist, diesen Fall analog der sog. Keratitis punctata superficialis anzusehen und aus diesem Befund den Schluss zu ziehen, dass die letzterwähnte Krankbeit auf Einwanderung von Mikroorganismen beruht, wie der Autor das thut, das erscheint uns zweifelhaft.

In Bezug auf die Hornhauterkrankung bei Conjunctivitis diphteritica betont Coppez (Les conjonct. pseudomembraneuses 1897 Brüssel) neben der Wirkung verschiedener pyogener Mikroorganismen (Staphylocokken, Streptocokken) ganz besonders auch eine directe schädigende Toxinwirkung auf die Cornea.

Als den Erreger einer nach Staaroperation eingetretenen Hornhautvereiterung mit Panophthalmie beschreibt de Schweinitz neben eigenthümlichen nicht pathogenen. Bacillen, Staphylocokken. Er erinnert an die bekannten Befunde von Haab und Sattler, die als Erreger traumatischer Panophthalmie den Bacillus pyocyaneus fanden. Randolph (American Journal of the Med.-Sciences, 1893 S. 440) fand in einem ähnlichen Falle das Bact. coli commune. Gerade die Erreger der operativen Wundinfectionen kennen wir bisher relativ wenig, so dass weitere Mittheilungen erwünscht sind. Wir können uns nicht wundern, dass unter ihnen bei Lappenvereiterungen und Panophthalmieen auch der Pneumococcus sich findet, da man wegen der meist gänzlich anderen Läsion ein Ulcus serpens gar nicht erwarten kann. Die uns bekannten Bestimmungen der Erreger von Operationsinfectionen sind bisher ausser den eben citirten 
die von Terson - Gabrielides ${ }^{1}$ ) (1 Mal Ozaenabacillen, 1 Mal Staphyl. pyog. aur.), von Gasparrini ${ }^{2}$ ) (1 Mal Pneumocokken), Pablowska ${ }^{3}$ ) (Bacillen), Evetzky und Berestneff ${ }^{4}$ ) (Pneumocokken), ohne dass diese Fälle besondere Verschiedenheiten geboten hätten. Wir selbst haben kürzlich eine schleichende Wundinfection untersucht und dabei neue Bacillen gefunden, uiber die an anderer Stelle näher berichtet werden soll.

Geht aus den mitgetheilten Literaturfällen von neuem hervor, dass die anderen Mikroorganismen weniger typische Eiterungen in der Hornhaut erzeugen, so liegen andererseits auch einige neuere Mittheilungen vor, welche die Bedeutung des Pneumococcus für das Ulcus corneae serpens vollauf bestätigen. Zunächst hat Secondi, wie wir nachträglich ersehen, auf Grund der von Basso angestellten und bereits früher von uns berücksichtigten Untersuchungen ausdrücklich betont, dass die klinischen Formen der Нypopyonkeratitis durch die Art der veranlassenden Mikroorganismen beeinflusst sein könne, und zwar schreibt auch er dem Pneumococcus das eigentliche Ulcus corneae serpens zu.

Auch Bach hat seinen bisherigen Standpunkt, dass die verschiedenen Formen der eiterigen Keratitis durch die gleiche Ursache und zwar vornehmlich die Staphylocokken entstünden, nunmehr aufgegeben. Wie er jetzt mittheilt, hat er die ätiologische Bedeutung der Pneumocokken bisher vorwiegend auf Grund von Thierexperimenten bestritten.

Es geht daraus zunächst hervor, dass es nicht gerechtfertigt ist, die Resultate zahlreicher am Menschen angestellter Untersuchungen, wie sie damals bereits vorlagen, auf Grund nur von Thierexperimenten zu bestreiten.

1) Archives d'ophthalm. 1894. XIV. S. 488.

2) Il diplococco di Fraenkel in patologia oculare. Atti della R. Accademia dei Fisio critici. Serie V, Vol. V, Siena 1894. S. 48 ff.

3) Archives of ophthalm. XXI. S. 22.

4) Med. Rundsch. 1895, Nr. 10 (ref. Centralbl.f. Augenh. 1895S. 266). 
Weitere Beiträge z. Bakteriologie d. Keratitis des Menschen ete. 203

Auf der anderen Seite aber müssen wir die ausschliesslichen Staphylocokkenbefunde sowie die relativ häufigen negativen, die Bach bei einigen früheren Abimpfungen rom Menschen erhielt, in erster Linie auf Mängel der Untersuchungsmethoden zurückzuführen.

Wir möchten hier nochmals betonen, dass ein florides, fortschreitendes Ulcus serpens bei richtiger Entnahme aus dem eiterigen Rande, regelrechter Uebertragung und Brauchbarkeit des Nährbodens ein positives Resultat geben muss, wie das ja in der Natur der Sache liegt. Die negativen Resultate liegen nach unserer Ueberzeugung und Erfahrung in einem Mangel dieser drei Factoren, unter denen der Nährboden trotz aller Vorsicht am meisten in Betracht kommt. Wenn im Deckglas eines fortschreitenden Ulcus serpens z. B. sich massenhaft Pneumocokken finden, auf der Cultur aber nicht, so liegt dies sicher nicht an der mangelnden Lebensfähigkeit der Mikroben, sondern daran, dass ihnen der Nährboden, der sich bekanntlich schnell ändern kann, nicht zusagt, vorausgesetzt, das überhaupt brauchbares Material auf ihn übertragen ist. Solche Fälle dürfen nicht als negativ bezeichnet werden. Wir haben diesmal bei fast ausschliesslicher Blutserumbenutzung nie ein negatives Resultat gehabt und sind dadurch in unserer Ansicht bestärkt,' dass auch die wenigen negativen Fälle unserer ersten Untersuchungsreihe auf Untersuchungsfehlern beruhen. Dasselbe ist uns bei den relativ zahlreichen negativen Fällen der jetzigen Untersuchungsreihe von Bach und Neumann wahrscheinlich. Wir haben es z. B. erlebt, dass ein Agar, auf welchem anfangs die Pneumocokken wuchsen, nach 8-14 Tagen denselben schon nicht mehr zusagte. Bei Blutserum ist das viel seltener, obwohl es auch hier geschehen kann.

Das hauptsächliche Ergebniss der Bach-Neumannschen Arbeit ist aber das, dass sie den Pneumococcus als die wichtigste Aetiologie des Ulcus corneae serpens nun- 
mehr anerkennen; sie nennen dasselbe in der Einleitung sogar ,das Pneumocokkengeschwür".

Ein Irrthum von Bach ist es aber, wenn er behauptet, wir hätten die Eigenthümlichkeit der Pneumocokkenimpfkeratitis beim Kaninchen nicht genügend gewürdigt. Im Gegentheil ist dieselbe auf S. 104 ff. unserer Arbeit eingehend besprochen. Auch sind unsere Thierversuche keine Bestätigung derjenigen von $\mathrm{Bach}$, da dieselben einerseits längst vor dem Erscheinen der Bach'schen Arbeit fertig waren, andererseits wir aus ihnen im Gegensatz zu Bach gefolgert haben, dass der Thierversuch für die menschliche Keratitis nicht genügend sei.

Ganz kurz müssen wir hier noch die Arbeit von Gourlay erwähnen, da dieselbe in jeder Hinsicht als vollkommen verfehlt zu bezeichnen ist. Weder ist die klinische Abgrenzung der von ihm beschriebenen „Kératite purul. interstitielle aiguë“ gegenüber dem Ulcus serpens und dem „Unguis“(!) haltbar, da seine Form nur Stadien und Varietäten des Ulcus serpens darstellt, noch sind die Angaben über die Pathogenese z. B. des Hypopyons discutabel, da er die zahlreichen Experimentaluntersuchungen Leber's u. A. völlig vernachlässigt; noch auch sind seine bakteriologischen Annahmen irgendwie bewiesen. Wir können uns nicht davon ïberzeugen, dass in den betreffenden Departements die eiterige Keratitis einen besonderen Typus besitzt, wie Gourlay meint, sondern wir halten die Deutung, die er seinen Befunden giebt, für nicht zutreffend. Ebenso urtheilt der Referent in den Archives d'ophthalm. (1896, S. 263).

Schliesslich ist noch von Bedeutung, dass Gasparrini in seiner letzten. Mittheilung über die Bedeutung der Pneumocokken für das Auge hervorhebt, er habe den Pneumococcus öfters in sogenannten katarrhalischen Geschwüren gefunden, in seltenen Fällen als Theilerscheinung einer einfachen Pneumocokkenconjunctivitis, häufiger bei Trachomatösen und bei chronischer Conjunctivitis. Dass beim Tra- 
Weitere Beiträge z. Balteriologie d. Keratitis des Menschen ete. 205

chom, besonders bei pannöser Vascularisation der Hornhaut eine Pneumocokken-Infection in der That atypisch verlaufen kann, bestätigte uns eine Beobachtung, wo am Rande eines Pannus ein atypisches muldenförmiges Geschwür sich entwickelt hatte (cf. S. 188). Vielleicht auch werden manche die ersten Stadien der Pneumocokken-Infection, die noch nicht typisch serpiginös aussehen, als katarrhalisch bezeichnen.

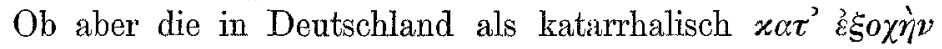
bezeichneten kahnförmgen Randgeschwüre durch Pneumocokken entstehen, dürfte zu bezweifeln sein. Einige von uns untersuchte Fälle haben sie uns nicht finden lassen.

\section{Literaturverzeichniss.}

Secondi, Sulla cheratite-ipopion. Clinica Moderna I, 1895. S. 42.

Ref. Michel-Nagel's Jahresbericht 1895.

Gourlay, Étude sur la kératite purulente interstitielle aiguë. Annales d'ocul. CXIII. 1. S. 22. 1895.

A badie, Étiologie et traitement des ulè̀res infectieux de la cornée. Annales d'ocul. CXIV. S. 88. 1895.

De Schweinitz, G. E., De certains bacilles trouvés dans un cas de panophthalmie postoperative. Annales d'oenl. CXIV. S. 55 . v. Korff, Beitrag zur Lehre vom Ule. corn. serp. Inang.-Diss. Kiel 1895.

Zirm, Ed., Keratomycose (beginnende Keratomalacie bei einem mit Lues congen. haemorrh. behafteten Säugling). Wiener klin. Wochensehrift 1895, Nr. 34, 35.

Hori, Zur Anatomie einer Ophthalmia hepatica. Arch. f. Augenh. XXXI. 1896. S. 393.

Kalt, Ulcérations cornéennes dans l'ophthalmie purulente; mode de propagation des microbes. Soe. de Biologie 7. Dee. 1895. Annales d'ocul. CXV. S. 61.

Bach, L. u. Neumann, R., Die eiterige Keratitis beim Mensehen. Arch. f. Augenh. XXIV. 1897. S. 267.

Morax, La conjontivite subaiguë. Ann. d'ocul. CXVII. 1897. Janv. Gasparrini, E., Bacteriologia della congiuntiviti acute. Atti del congresso oftalmologico di Venezia. 1895. Paria 1896.

Nuël, La kératite ponetuée superfieielle est une maladie microbienne. Archives d'ophthalm. 1896. Dec.

Coppez, Les conjonctivites psendomembraneuses. Bruxelles 1877. 


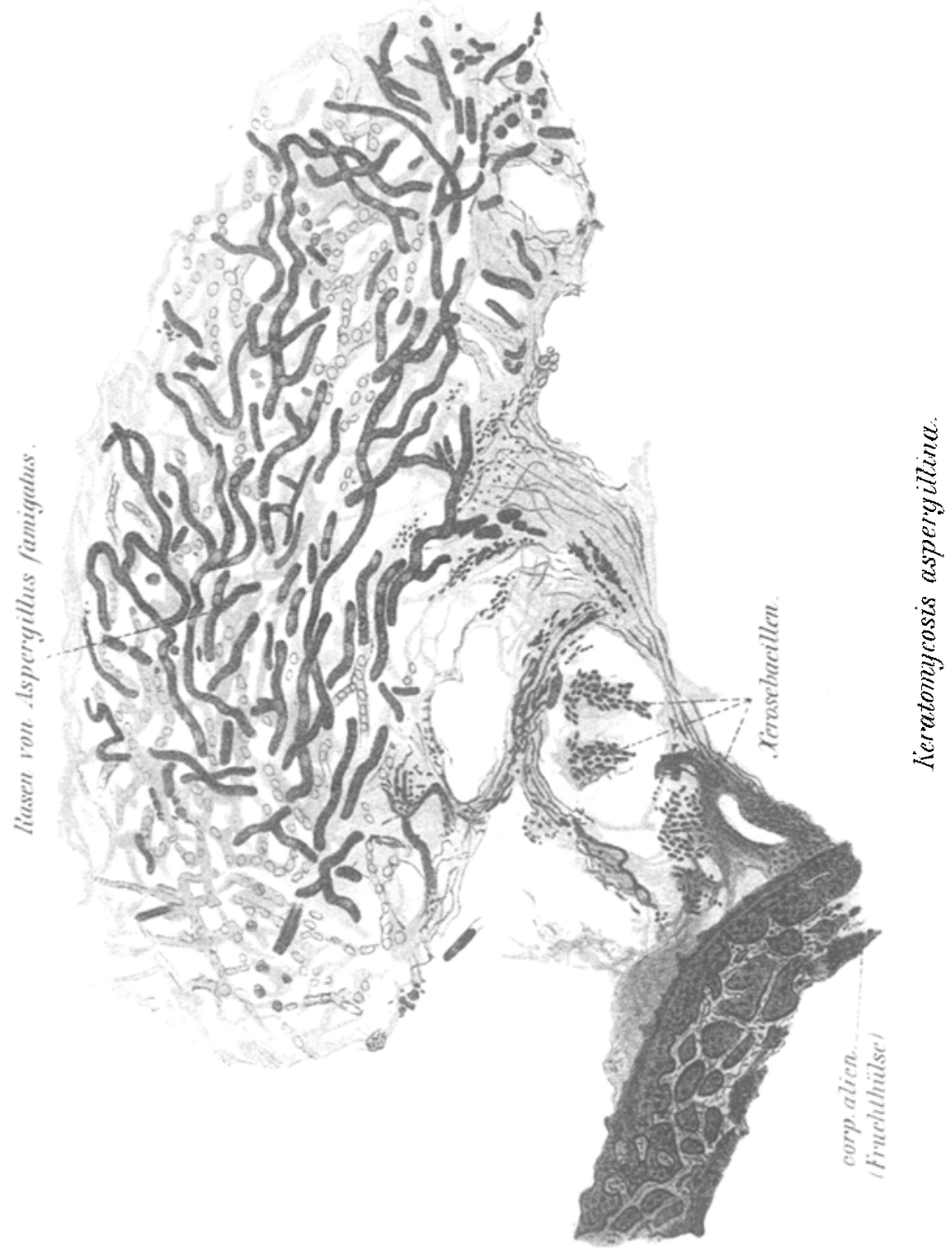

